\title{
Charge Transport and Photocurrent Generation Characteristics in Dye Solar Cells Containing Thermally Degraded N719 Dye Molecules
}

Andersen, Anders Rand; Halme, Janne ; Lund, Torben; Asghar, Muhammad Imran; Phuong, Nguyen Tuyet; Miettunen, Kati; Kemppainen, Erno; Albrektsen, Ole

Published in:

Journal of Physical Chemistry Part C: Nanomaterials and Interfaces

DOI:

10.1021/jp201658j

Publication date:

2011

Document Version

Early version, also known as pre-print

Citation for published version (APA):

Andersen, A. R., Halme, J., Lund, T., Asghar, M. I., Phuong, N. T., Miettunen, K., Kemppainen, E., \& Albrektsen, O. (2011). Charge Transport and Photocurrent Generation Characteristics in Dye Solar Cells Containing Thermally Degraded N719 Dye Molecules. Journal of Physical Chemistry Part C: Nanomaterials and Interfaces, 115(31), 15598-15606. https://doi.org/10.1021/jp201658j

\section{General rights}

Copyright and moral rights for the publications made accessible in the public portal are retained by the authors and/or other copyright owners and it is a condition of accessing publications that users recognise and abide by the legal requirements associated with these rights.

- Users may download and print one copy of any publication from the public portal for the purpose of private study or research.

- You may not further distribute the material or use it for any profit-making activity or commercial gain.

- You may freely distribute the URL identifying the publication in the public portal.

Take down policy

If you believe that this document breaches copyright please contact rucforsk@kb.dk providing details, and we will remove access to the work immediately and investigate your claim. 


\title{
Charge Transport and Photocurrent Generation Characteristics in Dye Solar Cells Containing Thermally Degraded N719 Dye Molecules
}

\author{
Anders Rand Andersen, ${ }^{*,+, \neq}$ Janne Halme, ${ }^{* *, \S}$ Torben Lund, ${ }^{\perp}$ Muhammad Imran Asghar, ${ }^{\S}$ \\ Phuong Tuyet Nguyen, ${ }^{\perp}$ Kati Miettunen, ${ }^{\S}$ Erno Kemppainen, ${ }^{\S}$ and Ole Albrektsen ${ }^{\dagger}$ \\ ${ }^{\dagger}$ Institute of Sensors, Signals and Electrotechnics (SENSE), The Faculty of Engineering, University of Southern Denmark, \\ Campusvej 55, DK-5230 Odense M, Denmark \\ ${ }^{\ddagger}$ Danish Technological Institute, Dept. of Plastics Technology, Taastrup, Gregersensvej 32630 Taastrup, Denmark \\ ${ }^{\S}$ New Energy Technologies, Department of Applied Physics, Aalto University, P.O. Box 15100, FIN-00076 Aalto, Finland \\ ${ }^{\perp}$ Department of Science, Systems and Models, Roskilde University, 4000 Roskilde, Denmark
}

Supporting Information

ABSTRACT: By deliberately introducing the thermally degraded form of the dye solar cell sensitizer N719 in dyesensitized solar cells (DSCs) using synthetically prepared N719-TBP $\left(\left[\mathrm{Ru}(\mathrm{L}-\mathrm{H})_{2}(\mathrm{NCS}) \text { (4-tert-butylpyridine }\right)\right]^{-+} \mathrm{N}$ $\left.(\mathrm{Bu})_{4}\right)$, we have investigated the devastating influence of this ligand substitution product (N719-TBP) on the performance parameters of the cells. Two types of dyed solar cells, based on either N719 or N719-TBP, have been characterized employing standard current-voltage $(I-V)$ performance test, UV-vis optical spectroscopy, incident photon to current efficiency (IPCE), and electrochemical impedance spectroscopy (EIS) methods. The performance tests show a drastic efficiency reduction of $~ 50 \%$ in the N719-TBP containing cells as compared to N719-dyed cells. The lower performance of N719-TBP was caused by lower overall light harvesting efficiency due to ca. $30 \mathrm{~nm}$ blue shift in the absorption spectrum of the dye, ca. $50 \%$ shorter electron diffusion length due to lower electron recombination resistance, and ca. $14 \%$ lower charge separation efficiency, which most likely can be ascribed to decreased dye regeneration efficiency caused by the replacement of one NCS ligand with TBP in the substitution product. The observations made in this study of DSC cells dyed with the substitution product, representing a worst case scenario of cells with $100 \%$ degraded dye, are in agreement with the characteristics of N719-dyed solar cells degraded at $85^{\circ} \mathrm{C}$, where the effect of ligand substitution is somewhat less pronounced.

\section{INTRODUCTION}

DSC appear to offer an attractive alternative to the currently market dominating types of silicon solar cells in terms of cost, and DSC has a range of new interesting possibilities for building integration and mobile applications, which makes industrialization further feasible. ${ }^{1,2}$ The worldwide efforts regarding DSC seem to be focused mostly at raising the efficiency and reducing the cost by using alternative materials or less material. However, the stability of a solar cell is equally as important as the efficiency and cost. A very important aspect in this context is the thermal stability of the DSC, which is why the cells in compliance with the IEC61646 standard repeatedly are subjected to heating cycles at $85^{\circ} \mathrm{C}$ in the dark, although it is debatable whether the IEC61646 standard is suitable for DSC.

The fact is that in maximum efficiency DSC that are usually based on solvent electrolyte and hydrophilic dyes such as the N719 and $\mathrm{N} 3$, a significant performance loss is induced after heating at $80^{\circ} \mathrm{C}$. $^{3}$

Regarding the mechanism for degradation it has previously been shown that the standard DSC sensitizer N719 reacts with liquid electrolyte contained species such as 4-tert butyl pyridine (TBP) at elevated temperatures in such a way that some amount of $\mathrm{Ru}(\mathrm{L}-\mathrm{H})_{2}(\mathrm{NCS})$ (4-tert-butylpyridine $\left.)\right]^{-+} \mathrm{N}(\mathrm{Bu})_{4}$, where $\mathrm{L}=2,2^{\prime}$-bipyridyl-4,4'-dicarbolylic acid, is formed on the surface of the $\mathrm{TiO}_{2}$ nano particles constituting the photo electrode (PE). We here refer to the substitution product as N719-TBP. The reaction has been investigated in much detail in DSC as well as test tube experiments. ${ }^{4-6}$ The TBP ligand is a frequently used electrolyte additive, which is used for its positive effect on the fill factor (FF) and the open circuit potential $V_{\text {OC }}$ of the solar cell. ${ }^{1}$

In this work, we study the characteristics of DSC when the sensitizer is either N719 or the thermal decomposition product N719-TBP. The model system is hence a worst case scenario and we seek to explain the dominating mechanisms that can be observed to different extents in DSC heating experiments (see Figure 1).

In this study, we have employed the DSC characterization techniques electrochemical impedance spectroscopy (EIS) and incident photon to current efficiency (IPCE). The EIS method involves measuring the electrical impedance $Z$ of the solar cell in

Received: February 19, 2011

Revised: April 14, 2011

Published: July 15, 2011 


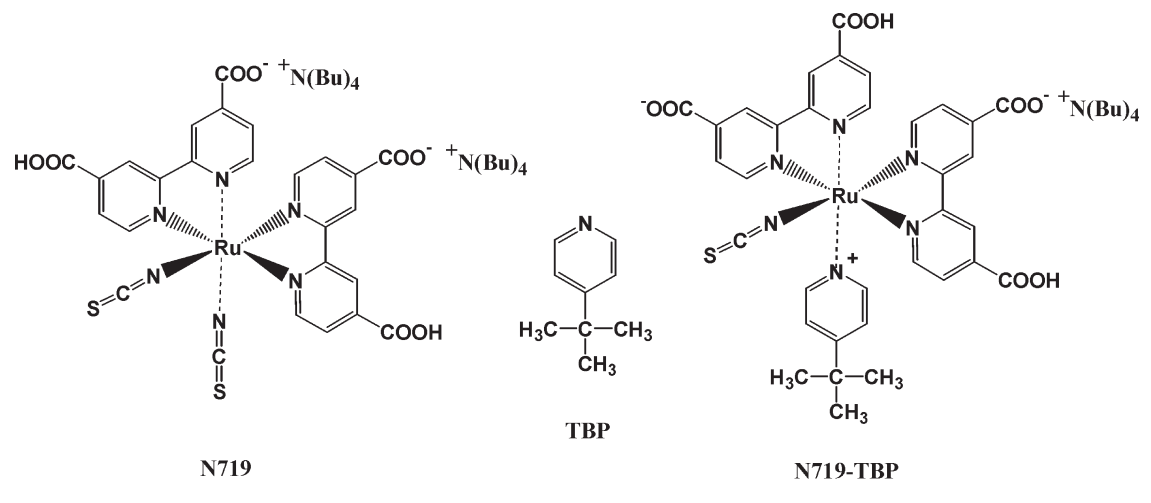

$\left[\mathrm{Ru}(\mathrm{L}-\mathrm{H})_{2}(\mathrm{NCS})_{2}\right]^{2-}, 2^{+} \mathrm{N}(\mathrm{Bu})_{4}$

$\left[\mathrm{Ru}(\mathrm{L}-\mathrm{H})_{2}(\mathrm{NCS})(\mathrm{TBP})\right]^{-+}{ }^{+} \mathrm{N}(\mathrm{Bu})_{4}$

Figure 1. Molecular structures of the N719 dye, the TBP ligand, and the N719-TBP degradation product.

a wide frequency range. Normally, it is done by setting the solar cell at some bias potential either in the dark or in the illuminated state, and by superimposing a small amplitude $(5-10 \mathrm{mV})$ sinusoidal voltage $V_{\mathrm{ac}}(\omega)$ the resulting current $i_{\mathrm{ac}}(\omega)$ can be measured. $\omega$ is the angular frequency. After recording the impedance spectra, a suitable electric model often can be fitted to the data. The model used here is a complete equivalent circuit involving a transmission line (TL) element, which is described in detail elsewhere. ${ }^{7,8}$ We will focus our attention to the following photo electrode (PE) model parameters:

$$
C_{\mu}=c_{\mu} d
$$

which is the chemical interface capacitance per unit volume $C_{\mu}$, related to electron density which depends on $\mathrm{TiO}_{2}$ Fermi level position. $d$ is the thickness of the $\mathrm{TiO}_{2}$ film.

$$
R_{\mathrm{T}}=r_{\mathrm{T}} d
$$

representing the transport resistance for charge transport through the $\mathrm{TiO}_{2}$ film $R_{\mathrm{T}}$ and expressed as the product of the transport resistivity $r_{\mathrm{T}}$ and $d$,

$$
R_{\mathrm{CT}}=r_{\mathrm{CT}} / d
$$

describing the charge transfer resistance related to interfacial recombination of electrons in the $\mathrm{TiO}_{2}$ /electrolyte interface per unit volume.

These three parameters describe the overall frequency dependence of the PE impedance and include all charge transfer interfaces and diffusion processes of the DSC PE. ${ }^{8}$

Two special cases of the TL element impedance for the $\mathrm{TiO}_{2}$ film are of special interest to this work. If $R_{\mathrm{CT}} \gg R_{\mathrm{T}}$, good current collection efficiency is present and the PE impedance can then be written:

$$
Z_{\mathrm{TiO}_{2}}=\frac{1}{3} R_{\mathrm{T}}+\left(\frac{R_{\mathrm{CT}}}{1+i \omega / \omega_{\mathrm{e}}}\right)
$$

where $\omega_{\mathrm{e}}=\tau_{\mathrm{e}}{ }^{-1}$ is the inverse of the electron lifetime $\tau_{\mathrm{e}}$. eq 4 is valid for low frequency, that is for $\omega<\omega_{\mathrm{d}}$, where $\omega_{\mathrm{d}}=1 / R_{\mathrm{T}} \mathrm{C}_{\mu}$.

The opposite case where $R_{\mathrm{CT}} \ll R_{\mathrm{T}}$, yields the following PE impedance:

$$
Z_{\mathrm{TiO}_{2}}=\left(\frac{R_{\mathrm{T}} R_{\mathrm{CT}}}{1+i \omega / \omega_{\mathrm{e}}}\right)^{1 / 2}=\frac{R_{\mathrm{G}}}{\left(1+i \omega / \omega_{\mathrm{e}}\right)^{1 / 2}}
$$

which is similar to the Gerischer impedance characterized by just one resistance, the Gerischer resistance $R_{\mathrm{G}}=\left(R_{\mathrm{T}} R_{\mathrm{CT}}\right)^{1 / 2}$. Fitting eq 5 to the PE data, one can obtain only the product of $R_{\mathrm{CT}}$ and $R_{\mathrm{T}}$, but not their values separately (Appendix I of ref 11 ).

The electron diffusion length in the $\mathrm{TiO}_{2}$ :

$$
L=\left(\frac{R_{\mathrm{CT}}}{R_{\mathrm{T}}}\right)^{1 / 2} d
$$

can be calculated based on the impedance parameters found by fitting the model to the spectra, but hence not for the case of a Gerischer impedance. It is noted that $R_{\mathrm{T}}$ can only be found for certain potentials, and hence in this study we could find transport resistance values around the maximum power point voltage, which is very normal. ${ }^{9}$

Another tool for charge transport analysis that is used here is based on the photocurrent generation performance of DSC. It is characterized by the incident-photon-to-collected electron efficiency (IPCE), $\eta_{\text {IPCE }}$, which is the product of three factors: the light harvesting efficiency $\eta_{\mathrm{LH}}$, the charge separation efficiency $\eta_{\mathrm{SEP}}$, and the electron collection efficiency $\eta_{\mathrm{COL}}$ as a function of wavelength $\lambda^{19}$

$$
\eta_{\mathrm{IPCE}}(\lambda)=\eta_{\mathrm{LH}}(\lambda) \eta_{\mathrm{SEP}}(\lambda) \eta_{\mathrm{COL}}(\lambda)
$$

To explain differences in the short circuit current density in different DSCs, these factors can be studied experimentally by a careful combination of IPCE and optical measurements analyzed with the so-called IPCE-ratio method. Note that the separation efficiency is a product of the electron injection efficiency $\eta_{\mathrm{INJ}}$ and the dye regeneration efficiency $\eta_{\mathrm{REG}}{ }^{19}$

$$
\eta_{\mathrm{SEP}}(\lambda)=\eta_{\mathrm{INJ}}(\lambda) \eta_{\mathrm{REG}}(\lambda)
$$

Unlike in our previous works, ${ }^{10,11} \eta_{\text {REG }}$ cannot be assumed $100 \%$ in the present work because the NCS substitution is anticipated to influence it. The highest occupied molecular orbitals of the N719 dye are situated at the NCS parts, and hence the NCS ligand they play a key role in the reduction of the oxidized dye by accepting electron from the redox electrolyte. ${ }^{12,13,14}$

The method is based on the fact that the ratio of the IPCE spectra measured from opposite sides of the cell (PE and CE sides), and corrected for differences in optical losses between the two directions, equals the ratio of the electron collection efficiencies

$$
\frac{\eta_{\mathrm{COL}, \mathrm{CE}}(L, d, \alpha(\lambda))}{\eta_{\mathrm{COL}, \mathrm{PE}}(L, d, \alpha(\lambda))}=\frac{T_{\mathrm{TCO}}(\lambda)}{T_{\mathrm{CE}}(\lambda) T_{\mathrm{EL}}(\lambda)} \cdot \frac{\eta_{\mathrm{IPCE}, \mathrm{CE}}(\lambda)}{\eta_{\mathrm{IPCE}, \mathrm{PE}}(\lambda)}
$$


that is it is independent of $\eta_{\mathrm{INJ}}$ and $\eta_{\mathrm{REG}}$, which are assumed position-independent constants. In the above equation, $T_{\mathrm{TCO}}$, $T_{\mathrm{CE}}$, and $T_{\mathrm{EL}}$ are the transmittances of the TCO glass substrate of the PE, the counter electrode (CE), and the bulk electrolyte layer (EL). ${ }^{11}$ The collection efficiency ratio (left-hand side of the above equation) is expressed as an analytical function of the electron diffusion length $(L)$, and the thickness $(d)$ and light absorption coefficient $(\alpha)$ of the PE film (eq B1 of ref 10). If the electron collection in the measured solar cells is less than perfect $(L<3 d)$, and light is absorbed relatively strongly in the film $(\alpha d>1)$, this ratio becomes sensitive on the value of $L$, making it possible to derive an estimate for it by fitting the expression to the experimental data (right-hand side of the equation). After determining $L$ this way, $\eta_{\text {SEP }}$ is estimated as ${ }^{10,19}$

$$
\eta_{\mathrm{SEP}}(\lambda)=\frac{\eta_{\mathrm{IPCE}, \mathrm{PE}}(\lambda)}{\eta_{\mathrm{LH}, \mathrm{PE}}(\lambda, d) \eta_{\mathrm{COL}, \mathrm{PE}}(L, d, \alpha(\lambda))}
$$

using the measured $\eta_{\mathrm{IPCE}}$ and $\eta_{\mathrm{COL}}$ calculated from the analytical expression (eq A11 of ref 10). The light-harvesting efficiency in eqs 8 and 9 is estimated from the optical data as

$$
\eta_{\mathrm{LH}, \mathrm{PE}}=T_{\mathrm{TCO}}\left[1-r_{\mathrm{PE}}\right] \frac{\alpha_{\mathrm{D}}}{\alpha}\left(1-e^{-\alpha d}\right)
$$

for the PE illumination $\left(\alpha_{D}\right.$ is the absorption coefficient of the dyed PE) and as

$$
\eta_{\mathrm{LH}, \mathrm{CE}}=T_{\mathrm{CE}} T_{\mathrm{EL}}\left[1-r_{\mathrm{PE}}\right] \frac{\alpha_{\mathrm{D}}}{\alpha}\left(1-e^{-\alpha d}\right)
$$

for the CE illumination, where $r_{\mathrm{PE}}$ is the reflectance of the $\mathrm{TiO}_{2}$ PE film.

$$
\alpha(\lambda)=\alpha_{D}(\lambda)+P \varepsilon(\lambda) \alpha_{E L}(\lambda)
$$

where $\alpha_{E L}(\lambda)$ is the absorption coefficient of the free electrolyte solution, $P$ is the porosity ( $P=0.6$ is used in the analysis) of the $\mathrm{TiO}_{2}$ film, and $\varepsilon$ is the average optical mean path length parameter that accounts for increase in the average path length of light due to light scattering in the film $(\varepsilon=1.5$ is assumed here).

It should be noted that the above IPCE ratio model and analysis assumes that both $\eta_{\mathrm{INJ}}$ and $\eta_{\mathrm{REG}}$ are position independent constant. This is very likely valid for $\eta_{\text {INJ }}$ that is not expected to depend significantly on the electron concentration in the $\mathrm{TiO}_{2}$. However, because $\eta_{\mathrm{REG}}$ represents loss of electrons due to recombination with the oxidized dye (due to too slow regeneration), it is proportional to the electron concentration, and hence, is position dependent due to the electron concentration gradient in the film at the short circuit condition. An accurate account of this would require numerical simulations of electron transport and recombination in the film, but are omitted here for simplicity. As a result, the $\eta_{\text {SEP }}$ estimated by the method (eq 9) should be taken as an effective mean value for the whole film.

Similarly, also the value of $L$ should be considered a mean effective value, first because the electron recombination may not be linear in electron concentration, as the above method assumes, and second because at the short circuit there is a concentration gradient of the tri-iodide that are the electron acceptors in dominant recombination reaction affecting $\eta_{\mathrm{COL}}$. These effects have been discussed and analyzed in detail recently by Piers et al. ${ }^{20,21}$

\section{EXPERIMENTAL SECTION}

Synthesis of Substitution Product. N719 was transferred to a three necked round-bottom flask equipped with a condenser and a gas bubbler. The powder was dissolved in DMF $(20 \mathrm{~mL})$ that contained TBP. The solution was deaerated with argon for 1 $\mathrm{h}$ and heated at $120^{\circ} \mathrm{C}$ under a small flow of argon. After $48 \mathrm{~h}$, water $(60 \mathrm{~mL})$ was added, and the diluted solution was eluted through a strong cation exchange column (Varian MEGA-BESCX, $1 \mathrm{~g}, 6 \mathrm{~mL}$ ) applying an IST Vac-Master connected to a water suction pump. DMF, the remaining N719, and other impurities were removed by washing with water and methanol. The product N719-TBP was eluted from the SCX column by an eluent comprised of hydrochloric acid/water/methanol (10:20:70). The SCX-eluent was diluted 10 times with water and eluted through a reverse phase $\mathrm{C} 18$ sep-pack column (Varian MEGA-BE-C18, $1 \mathrm{~g}, 6 \mathrm{~mL}$ ). The $\mathrm{C} 18$ column was carefully washed with a mixture of acetonitrile/water (10:90), and the substitution product was eluted with methanol. The methanol was removed by rotary evaporation and the product dried in a vacuum oven at $40{ }^{\circ} \mathrm{C}$. Further spectroscopic and chromatographic information can be found in the supporting information and in ref 22.

Solar Cell Preparation. The cell preparation began with the washing of photo and counter electrode substrates with a mild detergent and water to remove the organic impurities. The substrates were further given ultrasonic treatment in ethanol first and then in acetone. Substrates used are Pilkington TEC-15, thickness $2.5 \mathrm{~mm}$, sheet resistance $15 \Omega$ /sq., supplied by Hartford Glass Company, Inc. The PE was made by screen printing two layers of $\mathrm{TiO}_{2}$ paste (18NR-T, Dyesol). After printing each layer, the substrates were heated to $110{ }^{\circ} \mathrm{C}$ to dry the deposited layer. The PEs were fired at $450{ }^{\circ} \mathrm{C}$ for $30 \mathrm{~min}$. The area of each PE film was $A_{\text {cell }}=0.5 \times 0.8 \mathrm{~cm}^{2}=0.4 \mathrm{~cm}^{2}$. The thickness of the PE films was $14.1 \pm 0.8 \mu \mathrm{m}$ as measured by a Dektak $6 \mathrm{M}$ profilometer (Veeco).

Sensitization of the electrode films was done by soaking them in $0.3 \mathrm{mM}$ absolute ethanol solution of the dye for ca. $24 \mathrm{~h}$. All of the counter electrodes were prepared by thermal platinization method. A minute quantity of $10 \mathrm{mM} \mathrm{PtCl}_{4}$ is rapidly spread on the FTO coated glass substrates to achieve uniform thickness. Later, the counter electrodes were sintered at $385^{\circ} \mathrm{C}$ for $15 \mathrm{~min}$. The electrodes were sealed together on a hot plate $\left(100{ }^{\circ} \mathrm{C}\right)$ using $25 \mu \mathrm{m}$ thick Surlyn 1702 thermoplastic polymer film as a spacer and sealant, and finally the cells were filled with liquid electrolyte. The electrolyte composed of $0.5 \mathrm{M} \mathrm{LiI}, 0.03 \mathrm{M} \mathrm{I}_{2}$, and $0.5 \mathrm{M}$ TBP in MOPN.

Measurements. $I-V$-curves were measured at $20{ }^{\circ} \mathrm{C}$ with a custom-built solar simulator consisting of ten $150 \mathrm{~W}$ halogen lamps as the light source, a temperature-controlled measurement plate, and a calibrated monocrystalline silicon reference cell with a KG5 colorglass filter with which the lamps could be adjusted to provide the standard light intensity of $100 \mathrm{~mW} / \mathrm{cm}^{2}$. Spectral mismatch correction was used to make the curves correspond with the standard AM1.5G equivalent illumination.

IPCE measurements were carried out in $\mathrm{dc}$ mode without bias illumination using Model QEX7 Solar Cell Spectral Response Measurement System from (PV Measurements, Inc.).

EIS spectra were recorded with Zahner Elektrik's IM6 Impedance Measurement Unit operated with Thales software. The impedance data was obtained in the dark at different bias voltages between 0 and $-0.8 \mathrm{~V}$, in the $100 \mathrm{mHz}$ to $100 \mathrm{kHz}$ frequency 


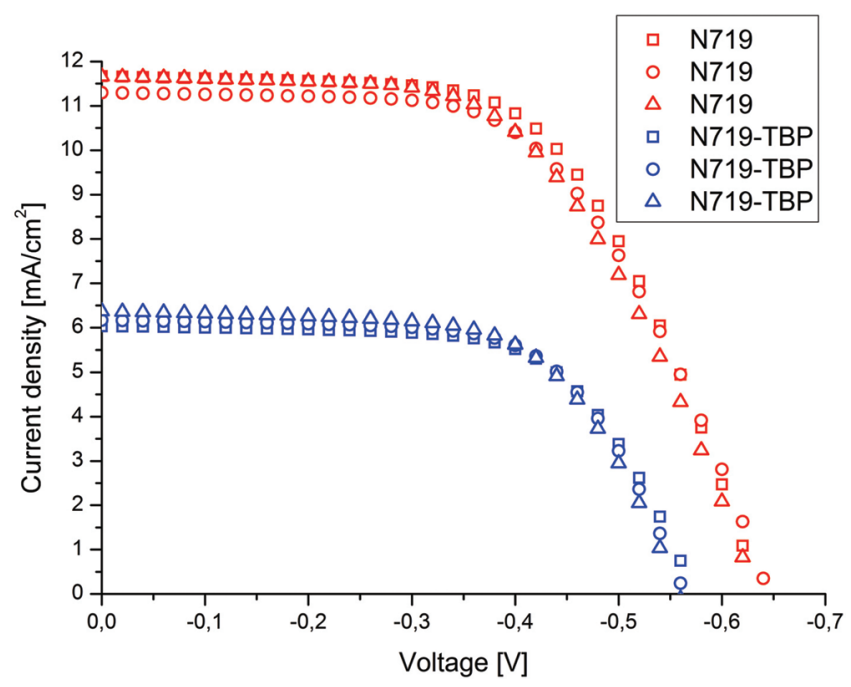

Figure 2. $J-V$ curves for three N719 cells and three N719-4TBP cells. As can be seen, the cell performance is drastically lowered by the ligand substitution in the N719 dye.

Table 1. Performance Parameters As Derived from the $J-V$ Curves Seen in Figure 2

\begin{tabular}{llclc}
\multicolumn{1}{c}{ dye } & $\eta(\%)$ & $\mathrm{FF}(\%)$ & \multicolumn{1}{c}{$V_{\mathrm{OC}}(\mathrm{V})$} & $J_{\mathrm{SC}}\left(\mathrm{mA} / \mathrm{cm}^{2}\right)$ \\
N719 & $4.3 \pm 0.1$ & $57.3 \pm 1.3$ & -0.65 & $11.7 \pm 0.2$ \\
N719-TBP & 2.2 & $63.3 \pm 0.3$ & $-0.57 \pm 0.01$ & $6.3 \pm 0.1$ \\
\hline
\end{tabular}

range. Zview software from Scribner Inc. was used for equivalent circuit fits of the EIS spectra.

Optical Characterization. Optical characterization of the cell components was carried out as in our previous publication. ${ }^{11}$ In short, each component (TCO glass, PE, electrolyte, counter electrode) was measured separately in an optical measurement cell in which the component in question is faced with a microscope glass slide, using a $25 \mu \mathrm{m}$ thick Surlyn foil frame as a spacer and sealant, and the cell is filled with the electrolyte solvent MOPN and sealed similar to the solar cells. The optical PE sample films consisted of ca. $7 \mu \mathrm{m}$ thick $\mathrm{TiO}_{2}$ nanoparticle film (same $\mathrm{TiO}_{2}$ paste as in the solar cells) deposited on a microscope glass slide and was dyed in the same dye bath as the films for solar cells. The reflectance $(R)$ and transmittance $(T)$ the optical cells were measured with a LI-COR LI-1800 spectroradiometer equipped with an integrating sphere in $390-1100 \mathrm{~nm}$ wavelength region. For reliable estimation of absorption coefficient of the dyed PE films $\left(\alpha_{D}\right)$ according to the Beer-Lambert law, the optical films needed to be relatively thin to avoid saturation of measured absorptance near the absorption maximum of the dye. Using the Beer-Lambert law, the light harvesting efficiency of the solar cells consisting of thicker (ca. $14 \mu \mathrm{m}$ ) PE films was estimated based on the value of $\alpha_{D}$ derived from the thinner optical films, which is valid for the present $\mathrm{TiO}_{2}$ films that show negligible light scattering. The optical data was also corrected for the loss of light via the sample substrates in the integrating sphere measurements.

\section{RESULTS AND DISCUSSION}

Solar Cell Performance. The efficiency of N719-TBP cells compared to N719 in the otherwise similar DSC is approximately $50 \%$ lower. In Figure 2, the performance parameters are shown for the 2 sets of 3 cells that had the most similar current density voltage $(J-V)$ curves. The FF is slightly higher for the degraded dye, whereas the maximum power point voltage is similar for the two types of DSC. The performance parameters are summarized in Table 1.

Electrochemical Impedance Spectroscopy. Six cells for each dye were prepared and impedance spectra were measured for $2 \times 3$ cells characterized in Figure 2. The impedance spectra obtained at various bias potentials in the dark for the two types of cells containing either N719 or N719-TBP sensitizer are very different in terms of the shape of the impedance Nyquist plots (Figure 3). The Nyquist plots (parts a and b of Figure 3) show that the impedance of the N719-TBP-dyed cells evolves into a Gerischer impedance, whereas the impedance of the N719-dyed cells maintain a dominating PE semicircle and diffusion characteristics. The latter indicates a better collection efficiency $\left(R_{\mathrm{CT}} \gg R_{\mathrm{T}}\right)$ in the N719-dyed cells. The impedance plotted in part a of Figure 3 is measured at $-0.55 \mathrm{~V}$, which is close the maximum power point voltage $\left(V_{\mathrm{MPP}}\right)$ and hence the data display an important characteristic difference that is the key to explaining the low efficiency of N719-TBP cells. At high enough negative potential, the N719-TBP PE Nyquist curves (parts $\mathrm{c}$ and $\mathrm{d}$ of Figure 3 ) evolve into a more pronounced semicircle indicating an improved charge collection efficiency. ${ }^{7}$

Figure 4 shows the imaginary part of the impedance versus frequency. The plot shows how the main PE peak is shifted toward higher frequencies and that the plot has lower amplitude. In Figures 3 and 4 data are reported as resistances multiplied by active cell area.

In Figure 5, we see the recombination resistance $R_{\mathrm{CT}}$ and $R_{\mathrm{T}}$ as a function of applied potential and the electron diffusion length $L$ is also plotted. Figure 5 show the Gerischer resistance $R_{\mathrm{G}}$ as found for N719-TBP cells using the full TL model. $R_{\mathrm{CT}}$ values are higher for the N719 cells at all intermediate potentials, in accordance with lower recombination and better performance.

$L$ is lower in the N719-TBP films (section on IPCE-ratio analysis) and increases with voltage, so in N719-TBP cells only a fraction of the whole film capacitance was actually measured at low and intermediate potentials. This is because when $L<d$, the electron current injected to the film from the contact in the EIS measurement, is transferred to the electrolyte within distance of ca. $L$ from the contact, and, hence, the rest of the film $(d-L)$ is electrically inaccessible by EIS measurement. ${ }^{8,9}$ Because the total PE resistance is much lower for N719-TBP cells than in the N719 cells, the condition $L<d$ is due to lower $R_{C T}$, instead of higher $R_{\mathrm{T}}$. A higher $R_{\mathrm{T}}$ would also result in a Gerischer shape, but then $R_{\mathrm{G}}$ would be larger than the value of $R_{\mathrm{CT}}$ in the N719 cells. Note that this qualitative conclusion can be drawn from the comparison of the shape and magnitude of the PE impedance arc, even though neither $L, R_{\mathrm{CT}}$, nor $R_{\mathrm{T}}$ can be estimated in this case (Appendices of refs 11 and 17). The Gerischer curve shape is observed in all N719-TBP cells up to $-0.55 \mathrm{~V}$ and for higher negative potentials the Nyquist curve shape becomes a more pronounced semicircle which indicates $L>d$, meaning that the $C_{\mu}$ values obtained at higher potentials are significant for the whole $\mathrm{TiO}_{2}$ film, whereas values at lower potentials should not be regarded as conclusive for the whole film. The diffusion length $L$ could be found for N719 cells and values are in the $20-50 \mu \mathrm{m}$ range. In the IPCE ratio analysis (next section), we find $L=$ $22.1 \pm 5.8 \mu \mathrm{m}$, so there is a good agreement between the two methods considering their different measurement principle and conditions. Exact correspondence of the IPCE and EIS derived values of $L$ has been recently confirmed by performing both 

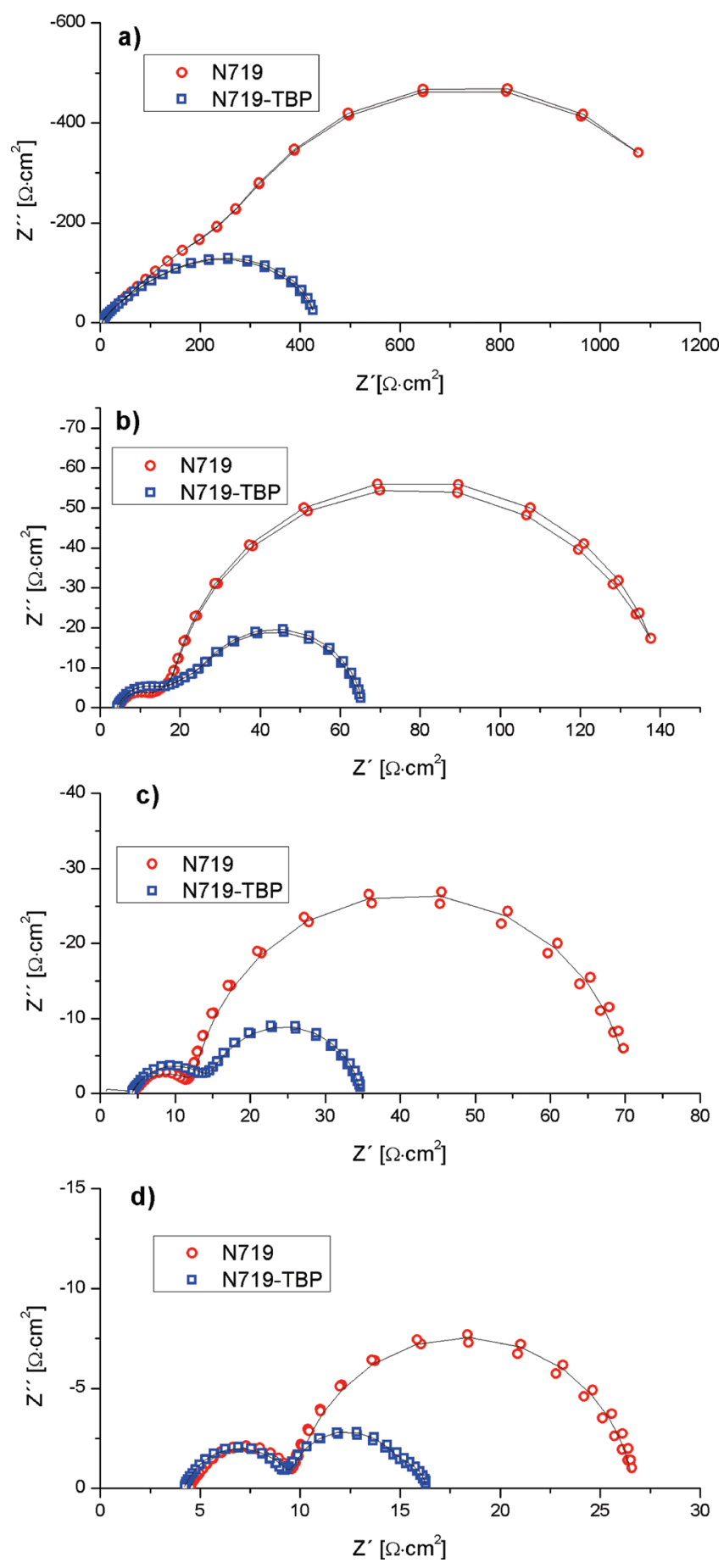

Figure 3. Nyquist plots showing EIS data for N719 and N719-TBP at 4 different bias potentials in the dark. Solid line is fit to equivalent circuit model. a) $V_{\text {cell }}=-0.45 \mathrm{~V}$, b) $V_{\text {cell }}=-0.55 \mathrm{~V}$, c) $V_{\text {cell }}=-0.6 \mathrm{~V}$, and d) $V_{\text {cell }}=-0.7 \mathrm{~V}$.

methods at the open circuit condition where the electron concentration in the PE film is close to uniform. ${ }^{19}$

Optical Analysis. Figure 6 shows that upon ligand substitution the absorptance spectra of the $\mathrm{N} 719$ attached on the $\mathrm{TiO}_{2}$ surface shifts (by ca. $30 \mathrm{~nm}$ ) toward shorter wavelengths, whereas the absorption maximum and the shape of the spectrum remain roughly the same. The absorption peak of N719 is at $540 \mathrm{~nm}$ and $\mathrm{N} 719-\mathrm{TBP}$ at $510 \mathrm{~nm}$.

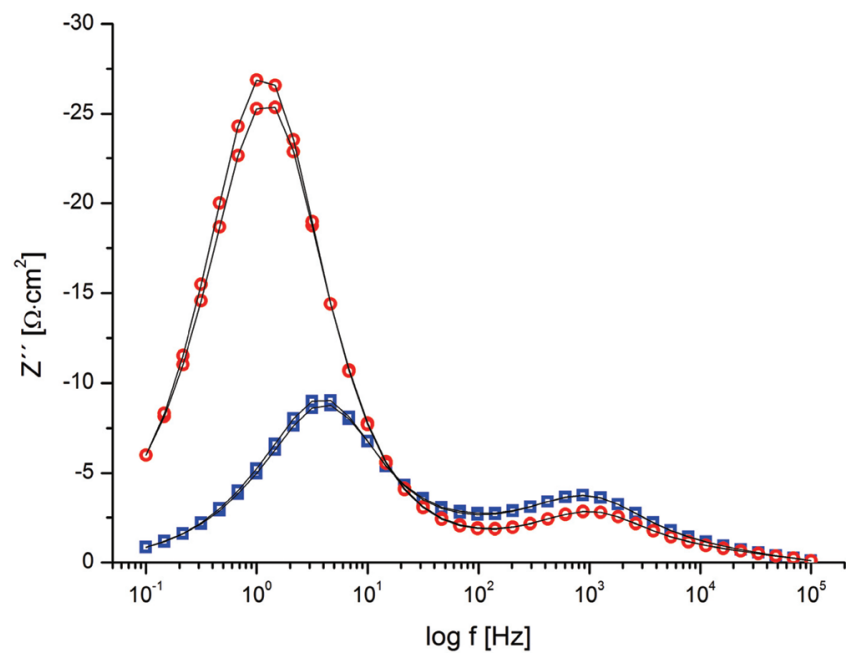

Figure 4. Imaginary part of the impedance $Z^{\prime \prime}$ plotted against frequency. Solid line is fit to an equivalent circuit model. The data were obtained at $-0.6 \mathrm{~V}$ bias in the dark. Squares are data for the N719 cell and circles are data for the N719-TBP cell. We can observe that the N719-TBP main peak (PE peak) is shifted toward higher frequency compared to the N719 peak, and the magnitude is lower.

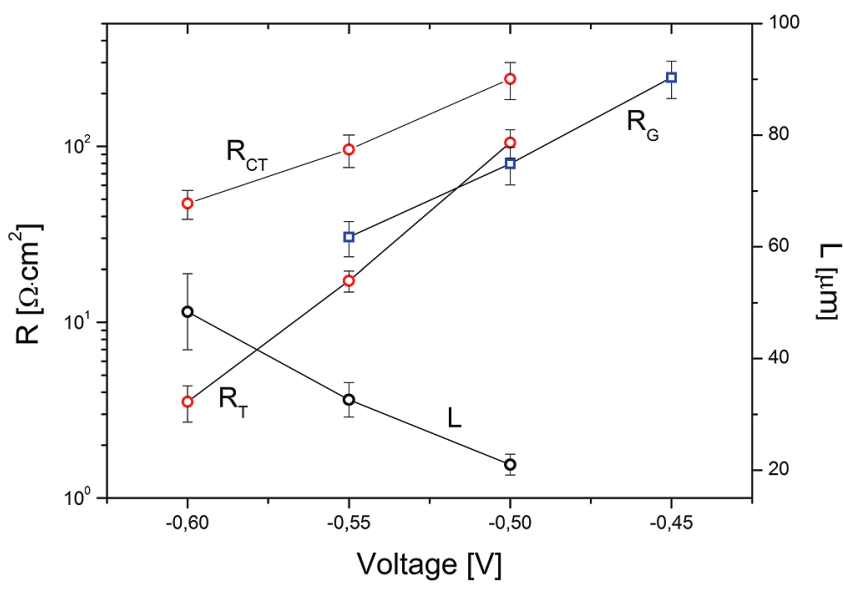

Figure 5. $R_{\mathrm{CT}}$ and $R_{\mathrm{T}}$ for N719 cells and the calculated diffusion length $L$ are plotted with error bars for standard deviation. $R_{\mathrm{G}}$ is plotted for N719-TBP cells in the voltage range where the Gerischer curve shape is observed.

IPCE Analysis. The measured IPCE data are shown and compared in Figure 7. For the N719, the IPCE measured from the PE side reaches a maximum of $70 \%$ around $540 \mathrm{~nm}$. This is a typical result for this dye. The lower IPCE as compared to some results in the literature ${ }^{1}$ is mainly due to the semitransparent $\mathrm{PE}$ used in this study and due to other optical losses.

From the comparison of parts a and $d$ of Figure 7, we can see that there is larger relative decrease in the IPCE when measured from the CE compared to PE side in the case of the substituted dye. Comparison of the IPCE ratio in Figure 8 clearly confirms this and implies directly that the solar cells dyed with N719-TBP suffer from lower $\eta_{\text {COL }}$ compared to the N719. This corresponds to shorter electron diffusion length, as shown quantitatively by the IPCE-ratio analysis in the next section, which is in agreement with the EIS results. 
Parts $b$ and e of Figure 7 show that the N719-TBP substitution decreases the IPCE over all measured wavelengths except in the $\mathrm{UV}$ region below $320 \mathrm{~nm}$ where the photocurrent is dominated

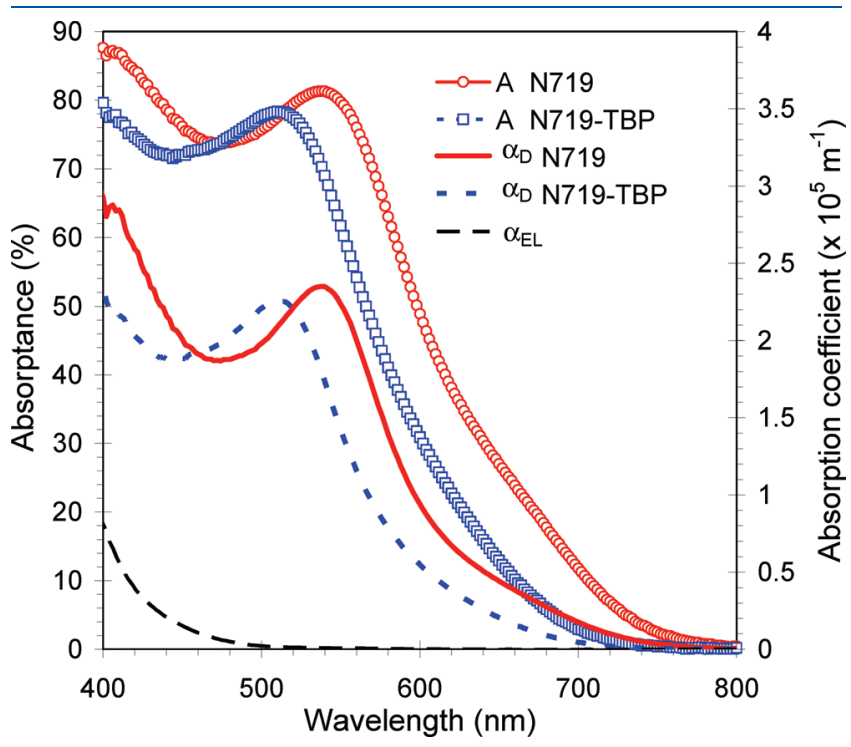

Figure 6. Measured absorptance spectra of $7 \mu \mathrm{m}$ thick dyed $\mathrm{TiO}_{2}$ films and the corresponding spectral absorption coefficient calculated using the Beer-Lambert law. The films were deposited on microscope glass slide and measured in a sealed optical cell containing MOPN. Also shown is the absorption coefficient of the electrolyte used in the solar cells. by electrons generated by the direct band gap excitation of the $\mathrm{TiO}_{2}{ }^{1}$. However, the relative decrease is larger at longer wavelengths (parts $\mathrm{c}$ and $\mathrm{f}$ of Figure 7), which causes a blue shift of the IPCE spectrum of N719-TBP relative to N719. This can be explained by the blue shift of the absorption spectrum of the dye upon TBP substitution (Figure 6). Note that a decrease of $\eta_{\mathrm{COL}}$ has the tendency to red shift the IPCE spectrum at the CE illumination. ${ }^{10,15}$ This effect is overruled here by the change in the optical absorption because a clear blue shift remains in part $\mathrm{f}$ of Figure 7 despite the lower $\eta_{\mathrm{COL}}$.

The very similar shape of the measured IPCE data (parts $\mathrm{c}$ and f of Figure 7) in different solar cell samples of the same kind indicates that they had closely equal PE film thickness. An exception is the sample N719-4, which displayed slightly redshifted IPCE spectrum, characteristic to a thicker $\mathrm{TiO}_{2}$ film (ref 10 for detailed discussion and experimental data on the effect of film thickness on the IPCE spectrum). This solar cell was opened, its PE thickness was measured, and indeed it had ca. $1 \mu \mathrm{m}$ thicker PE than the others on average. This value was used in the IPCE-ratio analysis discussed below (Table 2)

Figure 8 shows an example of the results from fitting the IPCE model to measured IPCE data using the IPCE-ratio method. A constant wavelength independent $L$ and $\eta_{\text {SEP }}$ was estimated performing a least-squares fit of the IPCE model to the optical and IPCE data in the wavelength region $500-600 \mathrm{~nm}$. The data below $500 \mathrm{~nm}$ was neglected as unreliable (bad fit of the IPCE model). The exact error source is unknown but seems to be related to the electrolyte absorbance. Above $600 \mathrm{~nm}$, the electron generation rate decreases toward longer wavelengths as the light absorption by the dye becomes weaker, which lowers the electron

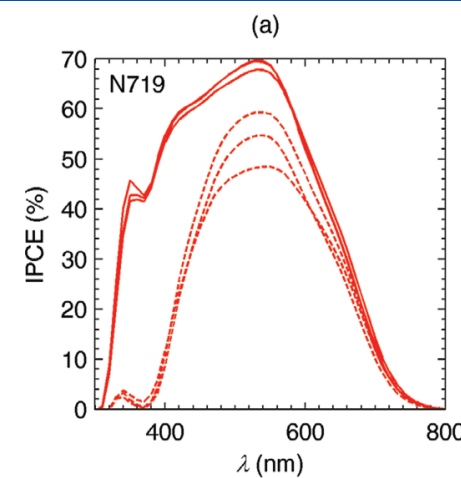

(d)

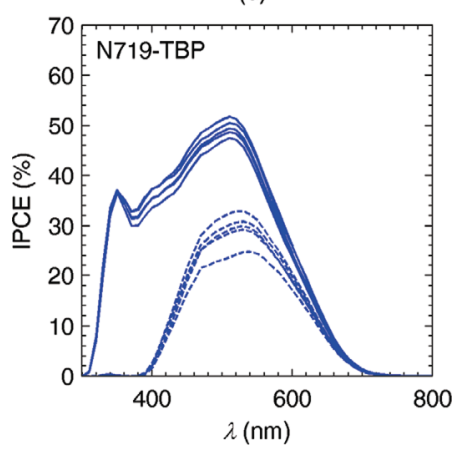

(b)

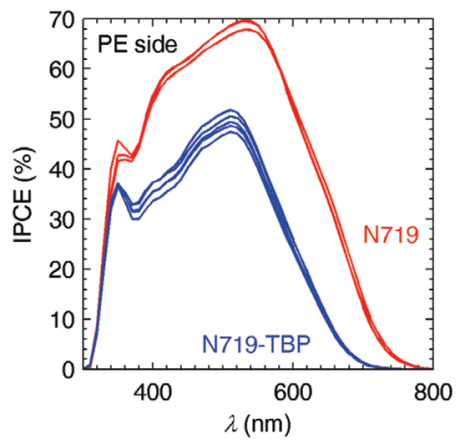

(e)

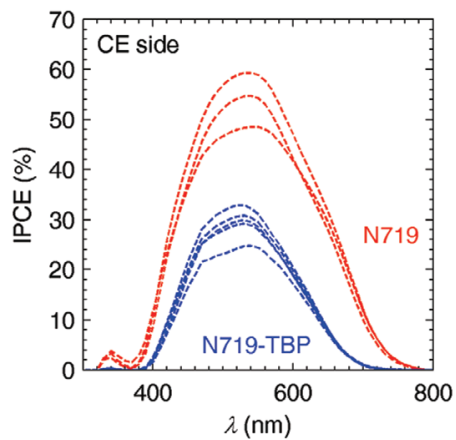

(c)

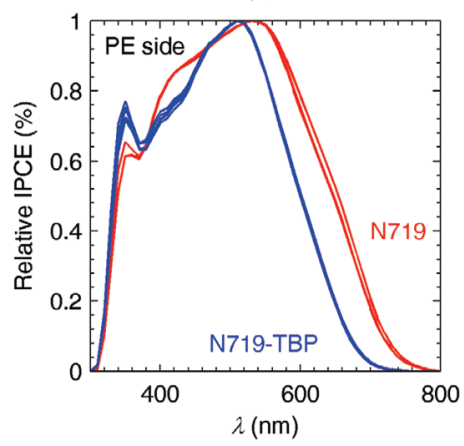

(f)

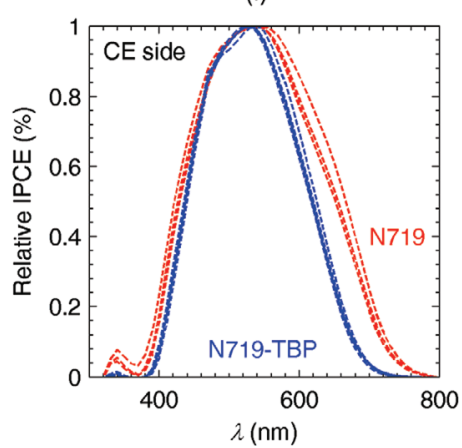

Figure 7. Comparison of the IPCE spectra of DSC with N719 dye (red) and N719-TBP dye (blue) measured from the PE side (line) and from the CE side (dashed line); a) and b) show that the relative difference between IPCE measured from the CE vs PE side is larger in the case of N719-TBP; b) and e) show that the effect of the TBP substitution decreases the IPCE over the whole measured wavelength range, above $320 \mathrm{~nm}$; c) and f) show change in the shape of the spectrum upon TBP substitution. 


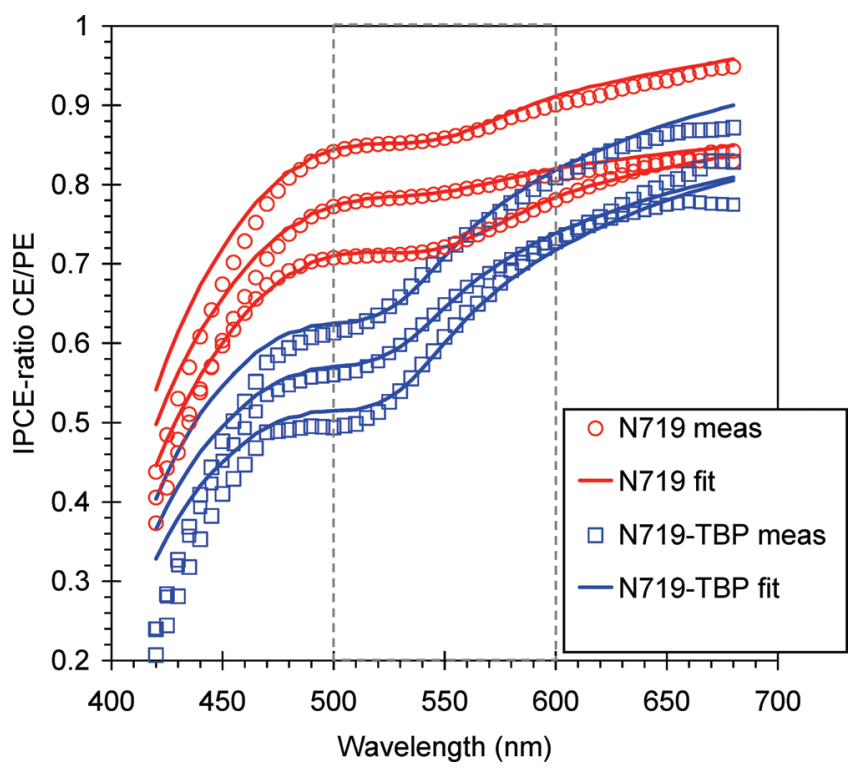

Figure 8. Measured and model fitted IPCE ratio $\left(\eta_{\mathrm{IPCE}, \mathrm{CE}} / \eta_{\mathrm{IPCE}, \mathrm{PE}}\right)$ for three solar cells with either N719 or N719-TBP dye. The dashed area shows the fitting region $(500-600 \mathrm{~nm})$.

Table 2. Results from the IPCE-Ratio Analysis Showing the Estimated Values of the Electron Diffusion Length $(L)$ and Separation Efficiency $\left(\eta_{\mathrm{SEP}}\right){ }^{a}$

\begin{tabular}{lcccc}
\multicolumn{1}{c}{ sample } & N719 & Stdev & N719-TBP & Stdev \\
$\boldsymbol{d}(\boldsymbol{\mu} \mathrm{m})$ & $\mathbf{1 4 . 1}$ & & $\mathbf{1 4 . 1}$ & \\
$\boldsymbol{L}(\boldsymbol{\mu} \mathrm{m})$ & $\mathbf{2 2 . 1}$ & 5.8 & $\mathbf{1 1 . 1}$ & 1.2 \\
$\boldsymbol{\eta}_{\mathrm{SEP}}(\%)$ & $\mathbf{9 1 . 2}$ & 3.1 & $\mathbf{7 7 . 0}$ & 1.6 \\
$\boldsymbol{\eta}_{\mathrm{IPCE}, \mathrm{CE}} / \boldsymbol{\eta}_{\mathrm{IPCE}, \mathrm{PE}}$ & $\mathbf{0 . 7 8}$ & 0.07 & $\mathbf{0 . 5 8}$ & 0.05 \\
$\boldsymbol{\eta}_{\mathrm{IPCE}, \mathrm{CE}}(\%)$ & $\mathbf{5 4 . 2}$ & 5.4 & $\mathbf{2 8 . 8}$ & 3.2 \\
$\boldsymbol{\eta}_{\mathrm{IPCE}, \mathrm{PE}}(\%)$ & $\mathbf{6 9 . 0}$ & 1.0 & $\mathbf{4 9 . 6}$ & 1.7 \\
$\boldsymbol{\eta}_{\mathrm{COL}, \mathrm{CE}}(\%)$ & $\mathbf{8 3 . 4}$ & 6.6 & $\mathbf{5 7 . 2}$ & 5.6 \\
$\boldsymbol{\eta}_{\mathrm{COL}, \mathrm{PE}}(\%)$ & $\mathbf{9 2 . 4}$ & 2.9 & $\mathbf{7 9 . 0}$ & 2.9 \\
$\boldsymbol{\eta}_{\mathrm{LH}, \mathrm{CE}}(\%)$ & $\mathbf{7 1 . 8}$ & 5.3 & $\mathbf{6 6 . 7}$ & 3.0 \\
$\boldsymbol{\eta}_{\mathrm{LH}, \mathrm{PE}}(\%)$ & $\mathbf{8 2 . 5}$ & 0.3 & $\mathbf{8 1 . 6}$ & 0.0
\end{tabular}

${ }^{a}$ Also shown are $\eta_{\text {IPCE }}, \eta_{\mathrm{COL}}, \eta_{\mathrm{LH}}$, and the IPCE-ratio at the absorption peak of the dye ( $540 \mathrm{~nm}$ for N719 and $510 \mathrm{~nm}$ for N719-TBP), as well as the PE film thickness $(d)$.

concentration in the $\mathrm{TiO}_{2}$. This appears to decrease the collection efficiency, yielding lower values for $L$. In the data (Figure 9), this can be seen as lower $\eta_{\text {IPCE }}$ values predicted by the model than actually measured above ca. $650 \mathrm{~nm}$. The same effect was found also previously ${ }^{10}$ and is presumed to be related to the absence of bias light in the measurements. The IPCE-ratio fitting was thus performed only within the region where the generation rate was relatively constant (Supporting Information).

In the present work, there were practical problems in obtaining a repeatable Pt coating of the counter electrodes (CE), because high air humidity during the preparation caused the Pt precursor solution to form droplets on the substrate, which upon drying resulted in nonuniform distribution of Pt. As a result, there was some variation of $\mathrm{CE}$ transmittance $T_{\mathrm{CE}}$ from one solar cell to another. This can be seen in the IPCE data that show much higher relative variation of the IPCE when measured from the $\mathrm{CE}$ side than from the PE side (parts $b$ and e of Figure 7). Error from

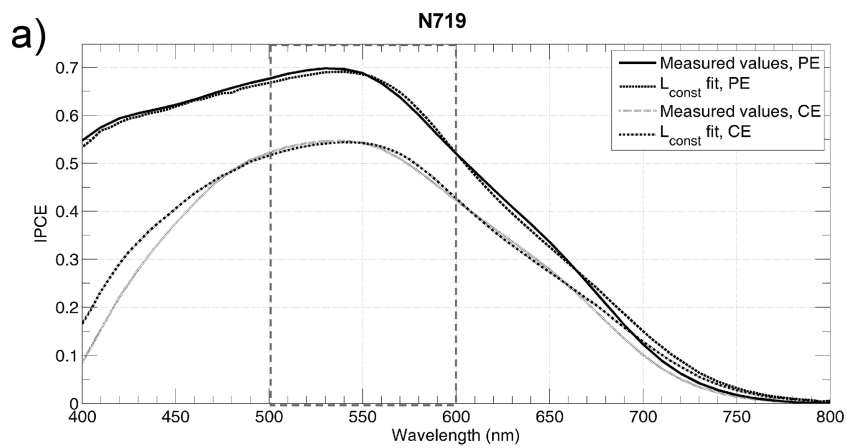

b)

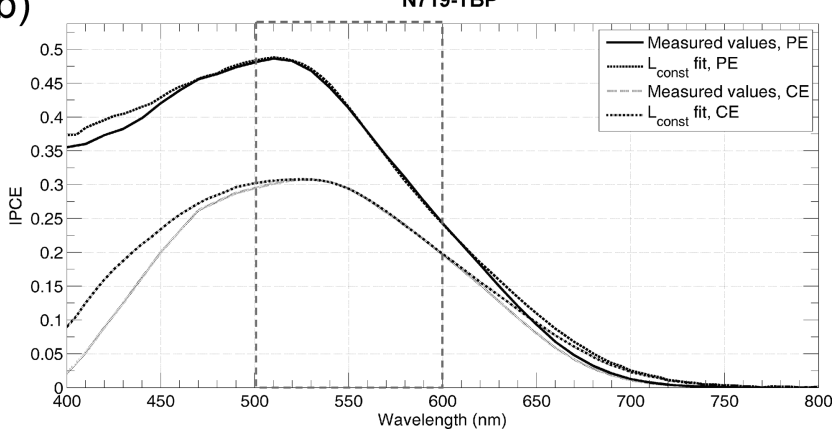

Figure 9. Comparison of the measured IPCE spectra of DSC with a) N719 and b) N719-TBP dye to the predicted IPCE spectra using constant (wavelength independent) $L$ and $\eta_{\text {SEP }}$ determined by the IPCE-ratio method. The dashed area shows the fitting region $(500-600 \mathrm{~nm})$.

this to the IPCE-ratio analysis was minimized by modifying the $T_{\mathrm{CE}}$ value slightly, using overall quality of fit as a criterion. Whereas this correction did not affect the overall conclusions, it decreased the standard deviation of the $L$ and $\eta_{\text {SEP }}$ estimates thus improving the accuracy of the results. Details of the correction procedure are given in the Supporting Information. Figure 9 shows the quality of fit in terms of the match between the measured IPCE-ratio and the IPCE-ratio predicted by the model using the fitted constant values of $L$ and $\eta_{\text {SEP }}$.

Table 2 shows that, upon TBP-substitution, $L$ was decreased by $50 \%$ (from $22 \pm 6 \mu \mathrm{m}$ to $11 \pm 1 \mu \mathrm{m}$ ). Because the PE films were $14 \mu \mathrm{m}$ thick, this lead to a significant decrease in $\eta_{\mathrm{COL}, \mathrm{PE}}$ from $92 \pm 3 \%$ to $79 \pm 3 \%$. In addition to lowering $L$, the ligand substitution decreased $\eta_{\mathrm{SEP}}$ from $91 \pm 3 \%$ to $77 \pm 2 \%$. We can summarize the effects of TBP ligand substitution on the photocurrent generation capability of the N719 dye by looking at the result for the PE illumination and the absorption maximum of each dye: the 19\%-units lower $\eta_{\text {IPCE }}$ of N719-TBP is explained by $26 \%$-units decrease in $\eta_{\mathrm{COL}}$ and $14 \%$-units decrease in $\eta_{\mathrm{SEP}}$, whereas $\eta_{\mathrm{LH}}$ remained practically unchanged (1\%-unit decrease). In other words, the $\eta_{\text {IPCE,PE }}$ of N719-TBP is lower by relatively $28 \%$ compared to $\mathrm{N} 719$ mainly because $\eta_{\mathrm{COL}}$ and $\eta_{\text {SEP }}$ are respectively lower by relatively $15 \%$ and $16 \%$. Besides the lower IPCE due to these factors the short circuit current density at AM1.5G solar illumination is further lowered by the blue shift of the IPCE spectrum of N719-TBP compared to N719. In practice, this means loss of optical performance at the longer wavelength, and thus lower overall $\eta_{\mathrm{LH}}$.

We have shown how the performance parameters and the internal PE parameters found by various measurements when applying the N719-TBP dye resemble what is found when heating complete DSC at $80-85^{\circ} \mathrm{C}^{3}$ The results are thus important for 
the further development as champion DSC are often based on N719 and dyes where we find two or even 3 NCS ligands coordinated to a molecular metal center. ${ }^{16}$

The synthesis and application of artificially degraded dyes has shown to be a valid method for studying degraded cells. Especially, the method aids in isolating effects solely caused by a degraded dye, which is valuable because heated cells often show a plural of different heating effects, making such cells difficult to analyze.

To explain the chemical origin of the lost performance induced by the ligand substitution in N719, we must mainly point at the most likely reason for lower $\eta_{\text {SEP }}$ in the N719-TBP cells. Although the present data does not provide experimental evidence to distinguish whether the lower $\eta_{\text {SEP }}$ with N719-TBP is due to lower $\eta_{\mathrm{INJ}}$ or $\eta_{\mathrm{REG}}$, it is reasonable to believe that at least $\eta_{\mathrm{REG}}$ is significantly lower with N719-TBP, since the NCS ligand has a key role in the dye regeneration reaction. ${ }^{12,13,14}$

\section{CONCLUSIONS}

DSC based on either N719 dye or the thermal substitution product N719-TBP $\left(\left[\mathrm{Ru}(\mathrm{L}-\mathrm{H})_{2}(\mathrm{NCS})(\mathrm{TBP})\right]^{-+} \mathrm{N}(\mathrm{Bu})_{4}\right)$ has been investigated using $J-V$ curves, optical and Raman analysis, EIS, IPCE and IPCE-ratio methods. The $J-V$ curves clearly show a very negative effect of ligand substitution and the cell efficiency is approximately $50 \%$ lower in all cases for the substituted dyes. $V_{\mathrm{OC}}$ as well as $J_{\mathrm{SC}}$ are both severely affected, while the overall shape of the $J-V$ curve is maintained. $J_{S C}$ was found smaller by IPCE analysis and lowered values are due to differences in optical, injection or regeneration, and collection efficiencies, with the latter two parameters being the most severely changed. $V_{\text {OC }}$ was found smaller due to differences in electron generation in the two types of cells, and the fact that charge transfer (recombination) resistance $R_{\mathrm{CT}}$ was higher for N719 cells.

The impedance measurements and model fitting show that all internal PE charge transfer parameters are affected in a negative way by the application of the degraded dye. For N719-TBP cells we observe that the PE resistance is well described by a Gerischer impedance, meaning that $L<d$ at intermediate potentials around the maximum power point, and we confirm that the charge transfer resistance $R_{\mathrm{CT}}$ is significantly lowered by the application of N719-TBP.

The overall light harvesting efficiency of N719-TBP was lower due to ca. $30 \mathrm{~nm}$ blue shift in its optical absorption spectrum. IPCE ratio analysis revealed that with N719-TBP the electron separation efficiency was ca. $14 \%$ lower, which in principle can be either due to lower electron injection or dye regeneration efficiency. Given the key role of the NCS ligand in the regeneration reaction, it is reasonable to believe that a major contribution came from lower dye regeneration efficiency with the N719-TBP due a missing NCS ligand. In addition to this, also the electron diffusion length was ca. $50 \%$ shorter leading also to lower electron collection efficiency with N719-TBP.

\section{ASSOCIATED CONTENT}

S Supporting Information. Capaticitance measurements, photocurrents in the IPCE measurements, and additional figures and tables. This material is available free of charge via the Internet at http://pubs.acs.org.

\section{AUTHOR INFORMATION}

\section{Corresponding Author}

*aran@sense.sdu.dk.

**janne.halme@tkk.fi.

\section{ACKNOWLEDGMENT}

This work is funded by Nordic Center of Excellence in Photo Voltaics and CNB-E project of the Aalto University research program Multidisciplinary Institute of Digitalization and Energy (MIDE).

\section{REFERENCES}

(1) Hagfeldt, A.; Boschloo, G.; Sun, L.; Kloo, L.; Pettersson, H. Dye-sensitized solar cells. Chem. Rev. 2010, 110, 6595-6663.

(2) Goncalves, L. M.; Bermudez, V.; Ribeiro, H. A.; Mendes, A. M. Dye-sensitized solar cells: A safe bet for the future. Energy Environ. Sci. 2008, 1, 655-667.

(3) Qing Wang, J.-E.; Moser; Grätzel, M. Electrochemical impedance spectroscopic analysis of dye-sensitized solar cells. J. Phys. Chem. B 2005, 109, 14945-14953.

(4) Nguyen, P. T.; Andersen, A. R.; Skou, E. M.; Lund, T. Photovoltaic Performance and Characteristics of Dye-Sensitized Solar Cells Prepared with the N719 Thermal Degradation Products $\left[\mathrm{Ru}(\mathrm{LH})_{2^{-}}\right.$ (NCS)(4-tert-butylpyridine) $]\left[\mathrm{N}(\mathrm{Bu})_{4}\right]$ and $\left[\mathrm{Ru}(\mathrm{LH})_{2}(\mathrm{NCS})(1\right.$-methylbenzimidazole $)]\left[\mathrm{N}(\mathrm{Bu})_{4}\right]$ Sol. Energy Mater. Sol. Cells 2010, 94, $1582-1590$.

(5) Nguyen, P. T.; Rikke D.; Nguyen, H. T. Torben Lund Thiocyanate ligand substitution kinetics of the solar cell dye Z-907 by 3-methoxypropionitrile and 4-tert-butyl pyridine at elevated temperatures. Sol. Energy Mater. Sol. Cells 2009, 93, 1939-1945.

(6) Nguyen, H. T.; Ta, H. M.; Lund, T. Thermal thiocyanate ligand substitution kinetics of the solar cell dye N719 by acetonitrile, 3-methoxypropionitrile, and 4-tert-butylpyridine. Sol. Energy Mater. Sol. Cells 2007, 91, 1934-1942.

(7) Fabregat-Santiago, F.; Bisquert, J.; Palomares, E.; Otero, L.; Kuang, D.; Zakeeruddin, S. M.; Michael, G. J. Correlation between photovoltaic performance and impedance spectroscopy of dye-sensitized solar cells based on ionic liquids. J. Phys. Chem. C 2007, 111 (17), 6550-6560.

(8) Bisquert, J.; Garcia-Belmonte, G.; Fabregat-Santiago, F.; Ferriols, N. S.; Bogdanoff, P.; Pereira, E. C. Doubling exponent models for the analysis of porous film electrodes by impedance. Relaxation of $\mathrm{TiO}_{2}$ nanoporous in aqueous solution. J. Phys. Chem. B 2000, 104 (10), 2287-2298.

(9) Wang, H.; Peter, L. M. A comparison of different methods to determine the electron diffusion length in dye-sensitized solar cells. J. Phys. Chem. C 2009, 113, 18125-18133.

(10) Halme, J.; Boschloo, G.; Hagfeldt, A.; Lund, P. Spectral characteristics of light harvesting, electron injection, and steady-state charge collection in pressed $\mathrm{TiO}_{2}$ dye solar cells. J. Phys. Chem. C 2008, $112,5623-5637$.

(11) Halme, J.; Vahermaa, P.; Miettunen, K.; Lund, P. Device physics of dye solar cells. Adv. Mater. 2010, 22, E210-E234.

(12) Hagfeldt, A.; Grätzel, M. Molecular Photovoltaics. Acc. Chem. Res. 2000, 33, 269-277.

(13) Florian Schiffmanna, J. V.V.; Huttera, J.; Urakawab, A.; Wirzb, R.; Baikerb, A. An atomistic picture of the regeneration process in dye sensitized solar cells. PNAS Early Edition, 4830-4833

(14) Rensmo, H.; Sodergren, S.; Patthey, L. et al.; The electronic structure of the cis-bis(4,4'-dicarboxy-2,2'-bipyridine)-bis(isothiocyanato) ruthenium(II) complex and its ligand 2,2'-bipyridyl-4,4'-dicarboxylic acid studied with electron spectroscopy, Chem. Phys. Lett. 1997, 274, 51-57. 
(15) Södergren, S.; Hagfeldt, A.; Olsson, J.; Lindquist, S. Theoretical Models for the Action Spectrum and the Current-Voltage Characteristics of Microporous Semiconductor Films in Photoelectrochemical Cells, J. Phys. Chem. 1994, 98, 5552-5556.

(16) Kong, F.-T.; Dai, S.-Y.; Wang, K.-J. Review of Recent Progress in Dye-Sensitized Solar Cells Hindawi Publishing Corporation, Advances in OptoElectronics, Volume 2007, Article ID 75384, 13 pages

(17) Miettunen, K.; Halme, J.; Vahermaa, P.; Saukkonen, T.; Toivola, M.; Lund, P Dye solar cells on ITO-PET substrate with $\mathrm{TiO}_{2}$ recombination blocking layers. J. Electrochem. Soc. 2009, 156, B876-B883.

(18) Agrell, H. G.; Lindgren, J.; Hagfeldt, A. Resonance Raman scattering of a dye-sensitized solar cell; mechanism of thiocyanato ligand exchange. J. Phys. Chem. B 2001, 105, 6314-6320.

(19) Jennings, J. R.; Li, F.; Wang, Q. J. Reliable Determination of Electron Diffusion Length and Charge Separation Efficiency in DyeSensitized Solar Cells. Phys. Chem. C 2010, 114, 14665-14674.

(20) Barnes, P. R. F.; Anderson, A. Y.; Juozapavicius, M.; Liu, L.; Li, X.; Palomares, E.; Fornelib, A.; O'Regana, B. C. Factors controlling charge recombination under dark and light conditions in dye sensitised solar cells. Phys. Chem. Chem. Phys. 2011, 13, 3547-3558.

(21) Barnes, P. R. F.; Anderson, A. Y.; Durrant, J. R.; O’Regan, B. C. Simulation and measurement of complete dye sensitised solar cells: including the influence of trapping, electrolyte, oxidised dyes and light intensity on steady state and transient device behaviour. Phys. Chem. Chem. Phys. 2011, 13, 5798-5816.

(22) Ngyen, P. T.; Thi Lam, B. X.; Andersen, A. R.; Hansen, P. E.; Lund, T. Photovoltaic performance and characteristics of dye sensitized solar cells prepared with the N719 thermal degradation products $\left[\mathrm{Ru}(\mathrm{L}-\mathrm{H})_{2}(\mathrm{NCS}) \text { (4-tert-butylpyridine) }\right]^{-},{ }^{+} \mathrm{N}(\mathrm{Bu})_{4}$ and $\left[\mathrm{Ru}(\mathrm{L}-\mathrm{H})_{2^{-}}\right.$ (NCS)(1-methylbenzimidazole) $]^{-},{ }^{+} \mathrm{N}(\mathrm{Bu})_{4}$. Eur. J. Inorg. Chem. 2011, 2533-2539. 